\title{
Quality of life and satisfaction with life of women who are childless by choice
}

\author{
Agnieszka Bień1, Ewa Rzońca', Grażyna Iwanowicz-Palus'1, Urszula Lecyk², Iwona Bojar \\ ${ }^{1}$ Department of the Basics of Midwifery, Faculty of Health Sciences, Medical University of Lublin, Lublin, Poland \\ ${ }^{2}$ Gynaecology and Obstetrics Unit with Maternity Ward, Independent Public Hospital, Radzyń Podlaski, Poland \\ ${ }^{3}$ Department for Woman Health, Institute of Rural Health, Lublin, Poland
}

Bień A, Rzońca E, Iwanowicz-Palus G, Lecyk U, Bojar I. Quality of life and satisfaction with life of women who are childless by choice. Ann Agric Environ Med. 2017; 24(2): 250-253. doi: 10.5604/12321966.1235181

\begin{abstract}
Objective. The study attempts to identify and analyze factors affecting the quality of life and satisfaction with life of women who are childless by choice.

Materials and method. The research instruments used were: the WHOQOL-Bref questionnaire and the Satisfaction with Life Scale (SWLS), and author's own questionnaire.

Results. A better overall quality of life, perception of own health and quality of life in all the specific domains analyzed was found among childless women living in cities, college/university-educated, and with a good or very good financial standing. Conclusions. A positive correlation was found between satisfaction with life and overall quality of life, general perceived health, and all quality of life domains. Higher satisfaction with life scores in childless women are correlated with a higher quality of life scores and better perceived health.
\end{abstract}

\section{Key words}

quality of life; satisfaction; voluntary childlessness; women

\section{INTRODUCTION}

Nowadays, the number of women deciding not to have children is increasing. This is due to socio-cultural transformations involving changing attitudes to professional life, focus on individuality and self-fulfillment, and acceptance of alternative forms of family life $[1,2]$.

The decrease in birth rates and increase in the number of women deciding not to have children are affected by a number of factors. These involve various aspects of a woman's life, and include: job insecurity, low earnings, unemployment, poor living conditions, continuing education, awareness of the costs related to having children, and advertising promoting various methods of contraception [3]. In recent years, social acceptance of voluntary childlessness has become more widespread and, to some extent, desired. It is even being asking whether an increase in social acceptance could accelerate the spread of this phenomenon [4]. The decision to have or not to have children affects the whole life of an individual, improving or deteriorating general wellbeing, quality of life, and satisfaction with life [5].

\section{OBJECTIVE}

The present study attempts to identify and analyze the factors affecting the quality of life and satisfaction with life of women who, by choice, are childless.

Address for the correspondence: Grażyna Iwaniwcz-Palus, Department of the Basics of Midwifery, Faculty of Health Sciences, Medical University of Lublin, Staszica 4-6, 20-081 Lublin, Poland

E-mail: spupalus@gmail.com

Received: 17 May 2016; accepted: 15 March 2017; first published on June 2017

\section{MATERIALS AND METHOD}

The study was conducted in the first quarter of 2014 and included 108 women in Lublin Province (Poland) who have remained childless by choice. The inclusion criterion was the woman's conscious decision not to have children, unrelated to infertility or to health problems constituting contraindications to pregnancy. The study was approved by the Lublin Medical University Bioethics Committee (KE0254/282/2013). The research instruments used included: the WHOQOL-Bref (World Health Organization Quality of LifeBref), SWLS (Satisfaction with Life Scale) questionnaires.

\section{RESULTS}

The women's perceived general health was slightly better than their general quality of life: 3.89 vs. 3.85 . The women experienced the highest quality of life in the physical domain, and slightly worse in the social, environmental, and psychological domains (Tab. 1).

Table 1. Quality of life scores among the women studied

\begin{tabular}{lccc}
\hline Domains & Mean & Median & $\begin{array}{c}\text { Standard } \\
\text { Deviation }\end{array}$ \\
\hline General quality of life & 3.85 & 4.00 & 0.77 \\
\hline Perceived general health & 3.89 & 4.00 & 0.66 \\
\hline Physical domain & 78.31 & 81.00 & 11.50 \\
\hline Psychological domain & 64.28 & 69.00 & 14.55 \\
\hline Social relationships domain & 69.31 & 75.00 & 19.11 \\
\hline Environment domain & 67.14 & 69.00 & 12.26 \\
\hline
\end{tabular}

The statistical analyses performed in the study showed that respondents under the age of 39 had a better perception 
of their health $(\mathrm{p}=0.036)$ and experienced a higher quality of life in the physical $(\mathrm{p}=0.001)$ and psychological domains $(\mathrm{p}=0.004)$ than those over the age of 39 . The study also showed that respondents who lived in cities, or were college/ university-educated, reported a good or very good financial standing, had a better perception of their health and general quality of life, and higher quality of life scores in all domains than the remaining respondents $(\mathrm{p}<0.05)$. Married women had higher quality of life scores in the social domain than those who were single $(\mathrm{p}<0.0001)$ (Tab. 2).

The mean satisfaction with life score in the study group was $20.17( \pm 5.48)$. Higher satisfaction with life scores were obtained by respondents under the age of $39(\mathrm{p}=0.012)$, living in cities $(\mathrm{p}=0.001)$, who were college/university-educated

Table 2. Quality of life scores in relation to socio-demographic data and various aspects of childlessness

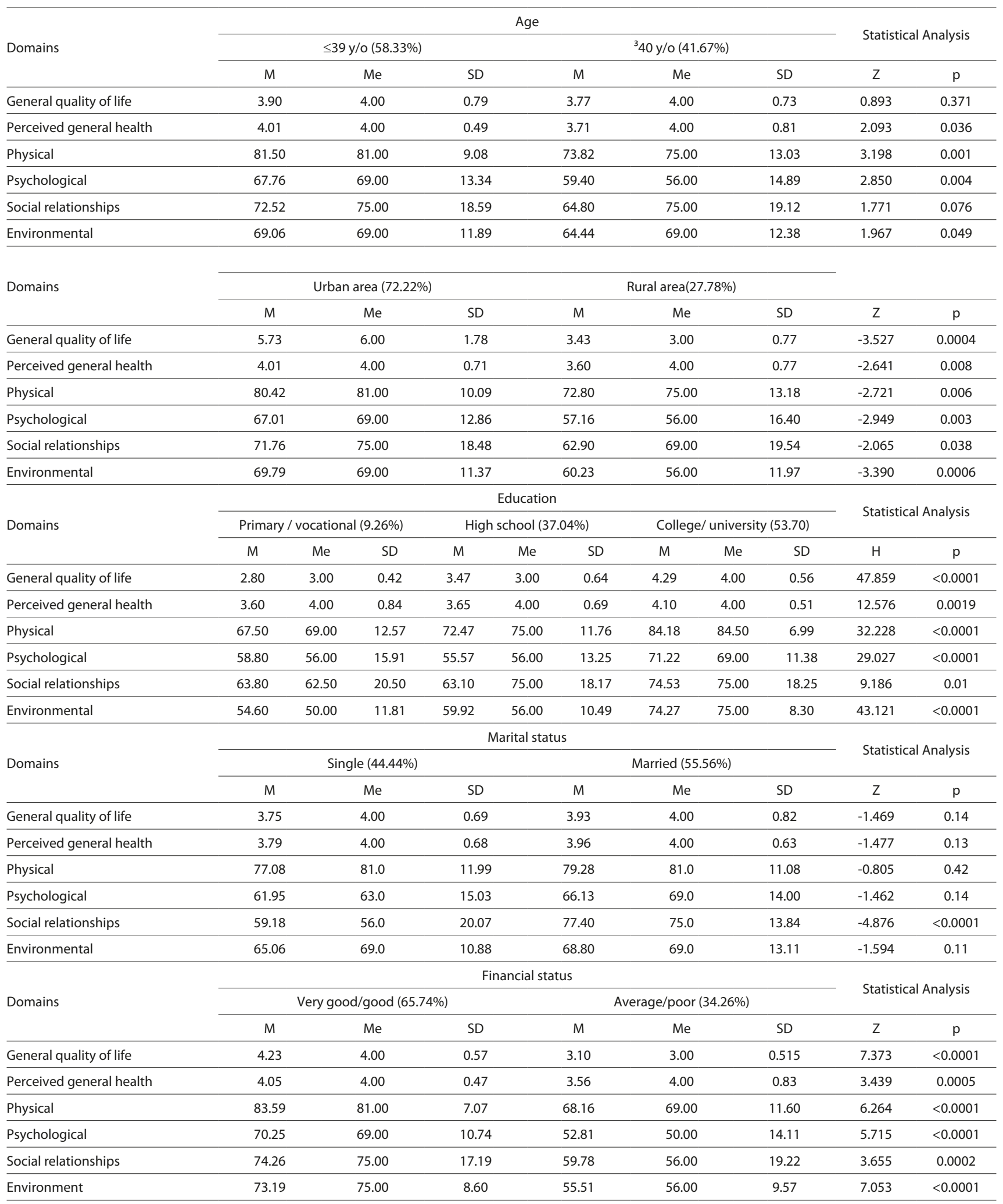


Table 3. Satisfaction with life scores in relation to socio-demographic data and various aspects of childlessness

\begin{tabular}{|c|c|c|c|c|c|}
\hline \multirow[t]{2}{*}{ Satisfaction with life (SWLS) } & Mean & $\begin{array}{c}\text { Median } \\
(\mathrm{Me})\end{array}$ & & \multicolumn{2}{|c|}{$\begin{array}{c}\text { Standard } \\
\text { Deviation (SD) }\end{array}$} \\
\hline & 20.17 & 21.00 & & \multicolumn{2}{|c|}{5.48} \\
\hline Socio-Demographic Data & M & Me & SD & \multicolumn{2}{|c|}{$\begin{array}{l}\text { Statistical } \\
\text { Analysis }\end{array}$} \\
\hline Age & & & & Z & $P$ \\
\hline$\leq 39$ y/o $(58.33 \%)$ & 21.28 & 22.00 & 5.25 & \multirow{2}{*}{2.494} & \multirow{2}{*}{0.012} \\
\hline${ }^{3} 40$ y/o (41.67\%) & 18.60 & 19.00 & 5.45 & & \\
\hline Residential area & & & & Z & $P$ \\
\hline urban $(72.22 \%)$ & 21.23 & 22.00 & 5.01 & \multirow{2}{*}{-3.185} & \multirow{2}{*}{0.001} \\
\hline rural (27.78\%) & 17.40 & 18.50 & 5.76 & & \\
\hline Education & & & & $\mathrm{H}$ & $P$ \\
\hline primary / vocational (9.26\%) & 15.50 & 15.00 & 4.48 & \multirow{3}{*}{31.033} & \multirow{3}{*}{$<0.0001$} \\
\hline high school (37.04\%) & 17.40 & 18.00 & 6.57 & & \\
\hline College / university (53.70\%) & 22.88 & 23.00 & 3.91 & & \\
\hline Marital status & & & & Z & $\mathrm{p}$ \\
\hline single (44.44\%) & 18.97 & 20.00 & 4.92 & \multirow{2}{*}{-2.382} & \multirow{2}{*}{0.017} \\
\hline married (55.56\%) & 21.11 & 22.50 & 5.75 & & \\
\hline Financial standing & & & & Z & $\mathrm{p}$ \\
\hline very good /good (65.74\%) & 22.70 & 23.00 & 4.15 & \multirow{2}{*}{6.645} & \multirow{2}{*}{$<0.0001$} \\
\hline Average /poor (34.26\%) & 15.29 & 15.00 & 4.31 & & \\
\hline
\end{tabular}

$(\mathrm{p}<0.0001)$, married, $(\mathrm{p}=0.017)$ and reported a good or very good financial standing ( $\mathrm{p}<0.0001)$ (Tab. 3).

Table 4 shows the relationship between the women's quality of life and satisfaction with life. A positive correlation was found between satisfaction with life and all specific quality of life domains $(\mathrm{p}<0.0001)$. Satisfaction with life was found to be correlated most strongly with quality of life in the psychological domain $(\mathrm{r}=0.721 ; \mathrm{p}<0.0001)$, general quality of life $(r=0.714 ; p<0.0001)$, and quality of life in the social domain $(r=0.702 ; \mathrm{p}<0.0001)$.

Table 4. Relationships between women's quality of life and satisfaction with life

\begin{tabular}{lcc}
\hline \multirow{2}{*}{ Domains } & \multicolumn{2}{c}{ Statistical Analysis } \\
\cline { 2 - 3 } & $\mathrm{r}$ & $\mathrm{p}$ \\
\hline General quality of life & 0.714 & $<0.0001$ \\
\hline Perceived general health & 0.400 & $<0.0001$ \\
\hline Physical & 0.621 & $<0.0001$ \\
\hline Psychological & 0.721 & $<0.0001$ \\
\hline Social relationships & 0.485 & $<0.0001$ \\
\hline Environmental & 0.702 & $<0.0001$ \\
\hline
\end{tabular}

\section{DISCUSSION}

In Poland, traditions related to family are held in high esteem, and mothers in general are highly regarded by many. The total fertility rate (TFR), however, is decreasing in Poland: it changed from 2.205 in 1978 and 2.416 in 1983 to 1.29 in 2013. In 2012, the percentage of childless 30 -year-old women in Poland was 40.4\%, twice that of 30-year-olds born in 1965. The percentage of childless 40 -year-old women was $17.5 \%$ [6].
The literature on this subject sometimes presents the view that parents are significantly happier and enjoy more social acceptance than those who do not have children, and that childlessness leads to feelings of failure and disappointment, which adversely affect one's wellbeing [7]. Other negative consequences of childlessness cited include feelings of loneliness, social exclusion, deteriorated health, and a higher risk of depression. Positive outcomes of childlessness are said to include increased freedom and independence, decreased stress, fewer responsibilities and daily concerns or financial worries $[1,5,8]$.

In the present study, the women's general quality of life was slightly lower than their perceived general health. However, Kendig et al. [9] and Włodarczyk and Ziółkowski [10] indicate that childless women are more likely to display behaviours harmful to their health, such as smoking, alcohol consumption or poor dietary habits, compared to those who have children. Meanwhile, Weir et al. [11] and Tamakoshi et al. [12] point to the medical aspects of childlessness. They report that childless women above the age of 40 are at a higher risk of developing breast cancer, and of death from cervical, ovarian or uterine cancer, than women who have children. Furthermore, in a study by McMunn et al. [13], 54-year-old childless women were shown to complain more often of poor health. Similarly, in the presented study, general perceived health was poorer among older women, above 40 , than among those under 40.

Holton et al. [14], analyzing the impact of childlessness on mental health, demonstrated that childless women had poorer mental health than mothers. Findings to the contrary were reported by McQuillan et al. [15] and Hansen et al. [5], who stated that being in a relationship had a stronger influence on psychological wellbeing than being a parent; therefore, support should target elderly individuals living alone, rather than the childless. This is in line with this author's own results, demonstrating that married women enjoyed a higher quality of life in the social domain than single respondents.

Vikström et al. [16] in their study on the impact of childlessness on psychological wellbeing and social relationships among the elderly, reported no psychological differences between 85-year-olds who had children and their childless counterparts. In the group of childless women, quality of life in the social domain, comprising such aspects as relationships with others and availability of support, was found to be dependent on socio-demographic factors, and was highest in married women, living in cities, college/ university-educated, and reporting good or very good financial standing.

A study performed in the American population demonstrated that childless individuals earned more and had accumulated more wealth than those who had children. These findings point to one significant factor affecting the quality of life and the wellbeing of childless adults [17]. The author's own results also showed that a good or very good financial standing was correlated with a better perception of one's general health and quality of life, and with higher scores in all quality of life domains.

In the next stage of the study, an attempt was made to determine whether socio-demographic factors and various aspects of a childless women's life affect satisfaction with life. In the literature on this subject, correlations were found between demographic factors, including age, gender, income 
and satisfaction with life. These correlations, however, were reported to be weak [18].

Analysis of relationships between satisfaction with life and selected socio-demographic factors in the presented study indicated that satisfaction with life among childless women depended on their age, place of residence, education, marital status, and financial standing. Lebrun et al. [19], in their study on a group of post-menopausal women, showed that being in a relationship improved the women's overall satisfaction with life. Furthermore, Holt-Lunstad et al. [20] reported that married individuals were more satisfied with their lives than single subjects. The authors also observed that satisfaction with life was improved by a good relationship between spouses, which decreased stress and depression.

In the presented study, the respondents' satisfaction with life was affected by their financial standing. Moderate or poor financial standing was correlated with one of the lowest satisfaction with life scores out of all the socio-demographic factors analyzed. These findings corroborate those reported by Abbott and Sapsford [21].

Some findings indicate that despite the women's conviction about their choice to remain childless, and despite their high quality of life and satisfaction with life, some long-term consequences should be considered. Childless women may be more likely to experience a deterioration of physical and psychological health, vitality, and social functioning in old age. Therefore, early preventive efforts targeting this group of women are advisable, aiming to resolve their current health problems and to prevent the deterioration of their health in the future. This could involve the development and implementation of appropriate public health strategies focused on childless women and their specific needs.

\section{CONCLUSIONS}

Factors affecting the quality of life and satisfaction with life reported by women who have decided to remain childless include their age, residence, education, marital status, and financial status. Higher satisfaction with life among childless women is correlated with higher quality of life scores and a better perception of their own health.

\section{REFERENCES}

1. Wanga H, Abbott DA. Waiting for Mr. Right: The meaning of being a single educated chinese female over 30 in Beijing and Guangzhou. Womens Stud Int Forum. 2013; 40: 222-229. doi:10.1016/j. wsif.2013.08.004.

2. Kreager P. Where are the children? In: Kreager P, Schröder-Butterfill E, editors. Aging Without Children: European and Asian Perspectives on Elderly Access to Support Networks. Berghahn Books, Oxford: 2005; p. 1-45.
3. Salles A, Rossier C, Brachet S. Understanding the long term effects of family policies on fertility: The diffusion of different family models in France and Germany. Dem Res. 2010; 22: 1057-1096. doi: 10.4054/ DemRes.2010.22.34.

4. Sobotka T, Testa MR. Attitudes and intentions toward childlessness in Europe. In: Höhn C, Avramov D, Kotowska IE, editors. People, population change and policies. Lessons from the Population Policy Acceptance study, Springer; 2008. p. 177-211.

5. Hansen T, Slagsvold B, Moum T. Childlessness and psychological well-being in midlife and old age: An examination of parental status effects across a range of outcomes. Soc Indic Res. 2009; 94: 343-362. doi: 10.1007/s11205-008-9426-1.

6. Central Statistical Office. Demographic Surveys and Labour Market Department. Population projection 2014-2050. Statistical analyses and studies. Warsaw 2014.

7. Hagestad GO, Call VRA. Pathways to childlessness - A life course perspective. J Fam Issues. 2007; 28: 1338-1361.

8. Graham ML, Hill E, Shelley JM, Taket AR. An examination of the health and wellbeing of childless women: A cross-sectional exploratory study in Victoria, Australia. BMC Womens Health. 2011; 10. doi: 10.1186/1472-6874-11-47.

9. Kendig H, Dykstra P, Van Gaalen R, Melkas T. Health of aging parents and childless individuals. J Fam Issues. 2007; 28: 1457-1486.

10. Włodarczyk P, Ziółkowski A. Having children and physical activity level and other types of pro-health behaviour of women from the perspective of the Theory of Planned Behaviour. Balt J Health Phys Act. 2009: 1: 143-149, doi: 10.2478/v10131-009-0017-6.

11. Weir R, Day P, Ali W. Risk factors for breast cancer in women. New Zealand Health Technology Assessment (NZHTA) Report 2007; 10 (2)

12. Tamakoshi A, Tamakoshi K, Lin Y, Mikami H, Inaba Y, Yagyu K, Kikuchi S. JACC Study Group. Number of children and all-cause mortality risk: results from the Japan Collaborative Cohort Study. Eur J Public Health. 2011; 21: 732-737. doi: 10.1093/eurpub/ckq175.

13. McMunn A, Bartley M, Kuh D. Women's health in mid-life: life course social roles and agency as quality. Soc Sci Med. 2006; 63: 1561-1572.

14. Holton S, Fisher J, Rowe H. Motherhood: is it good for women's mental health? J Reprod Infant Psychol. 2010; 28: 223-239. doi: 10.1080/02646830903487359.

15. McQuillan J, Greil AL, White L, Jacob MC. Frustrated fertility: Infertility and psychological distress among women. J Marriage Fam. 2003; 65: 1007-1018.

16. Vikström J, Bladh M, Hammar M, Marcusson J, Wressle E, Sydsjö G. The influences of childlessness on the psychological well-being and social network of the oldest old. BMC Geriatr. 2011; 11. doi: 10.1186/1471-2318-11-78.

17. Plotnick RD. Childlessness and the economic well-being of older Americans. J Gerontol B Psychol Sci Soc Sci. 2009; 64B: 767-776, doi:10.1093/geronb/gbp023.

18. Zagozdzon P, Kolarzyk E, Marcinkowski JT. Quality of life and rural place of residence in Polish women - population based study. Ann Agric Environ Med. 2011; 18(2): 429-432.

19. Lebrun CE, van der Schouw YT, de Jong FH, Pols HA, Grobbee DE, Lamberts SW. Relations between body composition, functional and hormonal parameters and quality of life in healthy postmenopausal women. Maturitas. 2006; 55: 82-92.

20. Holt-Lunstad J, Birmingham W, Jones BQ. Is there something unique about marriage? The relative impact of marital status, relationship quality, and network social support on ambulatory blood pressure and mental health. Ann Behav Med. 2008; 35: 239-244. doi: 10.1007/ s12160-008-9018-y.

21. Abbott P, Sapsford R. Life-satisfaction in post-soviet Russia and Ukraine. J Happiness Stud. 2006; 7: 251-287. doi: 10.1007/s10902005-5563-2. 